\title{
Clinical Supervision in Singapore: Allied Health Professional Perspectives from a two-round Delphi Study
}

\author{
Brena Lim \\ University of Canterbury, New Zealand, lim.bree@gmail.com \\ Kate Cook \\ University of Canterbury, New Zealand, kate.cook@canterbury.ac.nz \\ Dean Sutherland \\ University of Canterbury, New Zealand, dean.sutherland@canterbury.ac.nz \\ Alexandra J. Weathersby \\ University of Canterbury, New Zealand, alexandra.weathersby@canterbury.ac.nz \\ Gina D. Tillard \\ University of Canterbury, New Zealand, gina.tillard@icloud.com
}

Follow this and additional works at: https://nsuworks.nova.edu/ijahsp

Part of the Medicine and Health Sciences Commons

\section{Recommended Citation}

Lim B, Cook K, Sutherland D, Weathersby AJ, Tillard GD. Clinical Supervision in Singapore: Allied Health Professional Perspectives from a two-round Delphi Study. The Internet Journal of Allied Health Sciences and Practice. 2022 Jan 03;20(1), Article 12.

This Manuscript is brought to you for free and open access by the College of Health Care Sciences at NSUWorks. It has been accepted for inclusion in Internet Journal of Allied Health Sciences and Practice by an authorized editor of NSUWorks. For more information, please contact nsuworks@nova.edu. 


\title{
Clinical Supervision in Singapore: Allied Health Professional Perspectives from a two-round Delphi Study
}

\begin{abstract}
Purpose: This study investigated Allied Health Practitioners' (AHPs) perspectives on and consensus of clinical supervision in an acute tertiary hospital in Singapore. Specifically, AHPs' views on the benefits of and barriers surrounding engaging in clinical supervision, as well as strategies for enhancing clinical supervision experience. Method: A Delphi approach utilizing a two-round process via online questionnaires was employed. A total of 77 AHPs responded to the first round of the Delphi questionnaire and 55 AHPs completed the second round ( $71 \%$ retention rate). Open-ended responses from the first round underwent thematic analysis and resulted in sixty statements (five themes) describing engagement in clinical supervision. In the second round, AHPs were asked to rate each characteristic of clinical supervision on a 5 point Likert Scale. Results: Consensus was reached on 52 statements using a cut off of greater than $68 \%$ positive respondents and an interquartile deviation (IQD) $\leq 1$. The study identified 52 statements considered important for successful clinical supervision for AHP in an acute tertiary hospital in Singapore. Conclusions: The themes and underpinning statements provide insights about clinical supervision in the Singapore hospital setting.
\end{abstract}

\section{Author Bio(s)}

Brena Lim is a Speech-language pathologist working in Singapore. Brena completed her postgraduate qualification at the University of Canterbury.

Kate Cook is a Clinical Educator in the School of Psychology, Speech and Hearing I Te Kura Mahi ā-Hirikapo at the University of Canterbury, New Zealand.

Dean Sutherland, PhD, is an Associate Lecture in the School of Psychology, Speech and Hearing I Te Kura Mahi ä-Hirikapo at the University of Canterbury, New Zealand.

Alexandra Weathersby is a Clinical Educator in the School of Psychology, Speech and Hearing I Te Kura Mahi ā-Hirikapo at the University of Canterbury, New Zealand.

Gina Tillard is the Director of Clinical Education in the School of Psychology, Speech and Hearing I Te Kura Mahi ā-Hirikapo at the University of Canterbury, New Zealand. 


\title{
1IJAHSP ${ }^{m}$ \\ The Internet Joumnal of Allied Health Sciences and Practice \\ Dedicated to allied health professional practice and education \\ Vol. 20 No. 1 ISSN 1540-580X
}

\section{Clinical Supervision in Singapore: Allied Health Professional Perspectives from a two-round Delphi Study}

\author{
Brena Lim \\ Kate Cook \\ Dean Sutherland \\ Alexandra J. Weathersby \\ Gina D. Tillard \\ University of Canterbury \\ New Zealand
}

\begin{abstract}
Purpose: This study investigated Allied Health Practitioners' (AHPs) perspectives on and consensus of clinical supervision in an acute tertiary hospital in Singapore. Specifically, AHPs' views on the benefits of and barriers surrounding engaging in clinical supervision, as well as strategies for enhancing clinical supervision experience. Method: A Delphi approach utilizing a two-round process via online questionnaires was employed. A total of 77 AHPs responded to the first round of the Delphi questionnaire and 55 AHPs completed the second round $(71 \%$ retention rate). Open-ended responses from the first round underwent thematic analysis and resulted in sixty statements (five themes) describing engagement in clinical supervision. In the second round, AHPs were asked to rate each characteristic of clinical supervision on a 5-point Likert Scale. Results: Consensus was reached on 52 statements using a cut off of greater than $68 \%$ positive respondents and an interquartile deviation (IQD) $\leq 1$. The study identified 52 statements considered important for successful clinical supervision for AHP in an acute tertiary hospital in Singapore. Conclusions: The themes and underpinning statements provide insights about clinical supervision in the Singapore hospital setting.
\end{abstract}

Keywords: clinical supervision, Singapore, allied health, perspectives 


\section{INTRODUCTION}

Clinical supervision is a "...support mechanism for practicing professionals within which they can share clinical, organizational, developmental, and emotional experience with another professional in a secure, confidential environment in order to enhance knowledge of skills". ${ }^{1}$ Broadly, clinical supervision aims to provide individualised support, encourage reflective practice, and develop professional and clinical skills for the workplace.,2,3

There are several models of clinical supervision. Three examples specific to the health sector include 1) Proctor's Model of Clinical Supervision; 2) the CLEAR model, and 3) the "Growth and Support" model. ${ }^{1,4,5}$ These models differ in the terminology used and recommended structure of supervision sessions. Each model describes similar concepts that aim to scaffold the supervisee's professional and clinical learning and competence, promote confidence, reasoning, problem-solving and reflective practice skills.1,4${ }^{6}$ While these models provide overarching frameworks, implementation and modes of supervision varies across health care organisations. Approaches include supervision provided by an individual within the same profession, supervision from an individual from another profession; and, group or individual supervision sessions. Supervision can also vary in degree of formality, such as following a specific format at set times or less formal, spontaneous discussions. ${ }^{4,7}$ Recommendations for frequency of sessions are general and include "regular timings" and less than 3 months apart in order to support learning. 5,8 Knowledge of differing models of clinical supervision in healthcare is useful when considering whether organisations need to develop their own models of clinical supervision or can simply draw on such models to as part of their supervision education modules.

In countries such as New Zealand and Australia, while the requirements for clinical supervision vary based on the specific profession, clinical supervision for allied health professionals (AHP) working in healthcare is mandatory; however, this is not the case for AHP working in Singapore. ${ }^{9-11}$ In addition, clinical supervision is likely to be of higher quality and yield higher effectiveness in clinical teaching and learning when delivered in an educational and supportive environment, rather than in an environment perceived to be unsupportive by employees. ${ }^{12-15}$

\section{Benefits of Clinical Supervision}

Six benefits of clinical supervision for health care professionals have been reported. These are 1) improved job satisfaction; 2) prevention of burnout; 3) staff retention; 4) cost-effectiveness; 5) professional development of clinical skills; and (6) improved patient experience and outcomes. ${ }^{3,5,6,13,16-20}$ Clinical supervision has also been associated with effective leadership. $7,8,21$ Given the consistency with which the six benefits are identified, we assume that similar benefits of clinical supervision will be generated in this study with AHP in the acute hospital setting in Singapore or the Singapore context. This assumption, however, has yet to be investigated.

\section{Barriers to Clinical Supervision}

Despite the reported benefits of clinical supervision, a number of barriers to successfully engaging in clinical supervision exist. Clinical supervision has been described as time-consuming and a "management-monitoring tool". ${ }^{22-25}$ Nurses from the United Kingdom, Australia, New Zealand and America reported prioritizing caseloads and patient care over time spent engaging in clinical supervision. ${ }^{16,24}$ Clouder and Sellars reported physiotherapy, occupational therapy and nursing staff as having negative perceptions of clinical supervision, when time for supervision was not protected by the organisation, despite the known benefits for patient care. ${ }^{3}$ Poor relationships between medical supervisors and supervisees have also been linked with reduced patient care. ${ }^{26}$ Nursing supervisees in positions of authority have reported a reluctance to engage in clinical supervision due to a fear of perceived incompetence. ${ }^{19}$ Additionally, a lack of understanding by both supervisors and supervisees of their responsibilities and the rationale for engaging in supervision was reported as a further barrier. ${ }^{16,22,24,27-29}$ While a variety of barriers to engaging in clinical supervision exist, we argue that organisations (such as the current study's acute hospital setting) should develop knowledge of barriers specific to their workplace, in order to ensure clinical supervision is fit for purpose and supportive of both employer and employee goals. ${ }^{30}$ 32

Clinical

Supervision

in

Singapore

AHPs in Singapore include audiologists, dieticians, occupational therapists, physiotherapists, podiatrists, radiographers and speech-language therapists. ${ }^{10}$ Recent growth of these professions in Singapore has resulted in a significant increase in the number of younger and less experienced AHPs working in healthcare settings. ${ }^{33}$ The organisation of AHPs working in healthcare settings in Singapore is aligned with standard practices in other commonwealth countries. The Allied Health Professionals Council of Singapore requires all newly qualified AHPs to participate in clinical supervision for at least a minimum of 1 year before gaining full registration. ${ }^{10}$ The modes or models of supervision are not stated. Examples of what direct contact between supervisors and supervisees are suggested but not required. These include one-on-one performance feedback, case discussions, case audits, direct observations and case presentations. ${ }^{10}$ Therefore, each hospital has the autonomy to develop clinical supervision 
approaches to meet the needs of their workforce. ${ }^{30-32}$ However, the flexibility and lack of specificity inherent in regulations surrounding clinical supervision beyond the new graduate year, contradicts studies that suggest a framework and structure for supervision, with knowledge of potential paths for the supervisee's career, assists in making the environment more conducive to learning..$^{17,29}$

When comparing engagement in clinical supervision in Singapore to other commonwealth countries with a similar population size such as New Zealand, one finds that clinical supervision is mandated for all allied health staff, and not just new graduate allied health professionals, under the New Zealand Health Practitioners Competence Assurance Act (2003). ${ }^{9}$ Supporting the requirements in Singapore however, is the recommendation from the New Zealand and Australian contexts that organisations should construct their own clinical supervision training framework with supporting policies and procedures to allow for fit for purpose clinical supervision for their workplace requirements, and demonstrate organisational support for clinical supervision. ${ }^{30-32}$

In summary, the benefits of engaging in clinical supervision are well documented and include job satisfaction, prevention of burnout, staff retention, cost-effectiveness, professional development and improved patient safety, care and outcomes. $3.5,6,13,16-20$ Barriers to engaging in effective clinical supervision include a lack of knowledge of roles and responsibilities, time, prioritising patients over self, and human resourcing.,16,23-25,27-29 However, little is known if similar benefits and barriers are experienced by AHPs in Singapore. Similarly, the lived experiences of AHP engaged in clinical supervision in Singapore have not been examined, nor do guidelines exist for engaging in clinical supervision beyond new graduates' first year post-graduation. Given recommendations from both New Zealand and Australian contexts suggest ongoing engagement in clinical supervision, organisation-specific and fitfor-purpose clinical supervision guidelines, an investigation into the AHP perspectives of Singapore-based AHPs on clinical supervision in the hospital setting is warranted. Therefore, the current study aimed to investigate AHPs' perspectives on the current practices of clinical supervision, perceived benefits and barriers when engaging in clinical supervision, as well as strategies for enhancing clinical supervision in an acute hospital setting in Singapore.

\section{METHOD}

Ethics approval for this study was gained from the Centralized Institutional Board of Singapore (Singhealth) and a University Research Ethics Committee.

\section{Research Design}

The study utilized an observational study approach adhering to the Delphi technique. The Delphi technique has been used within a variety of health and education settings to predict trends, make decisions, gain consensus across disciplines and utilize a group of expert participants. ${ }^{21,34-40}$ The phrase "expert participants" allows the research team to define the parameters for participants in the study, to ensure participants have knowledge on the areas being investigated, such as the lived experience of clinical supervision as is the case for the present study. ${ }^{36}$ The Delphi technique was therefore selected in order to gain diverse and varied opinions from a number of different AHP about clinical supervision in their workplace, generate a consensus and correlate informed judgements in order to answer the research questions in the context of the Singapore hospital setting. ${ }^{36}$ Finally, the ability to gain candid and honest responses while protecting anonymity of AHPs currently in the workplace, was a further factor supporting the use of the Delphi technique. $35,38,40$ Two or three rounds of questionnaires seeking a combination of quantitative and qualitative response data are typically sufficient to reach consensus on the subject matter. ${ }^{21,36}$ For this study, two rounds of questionnaires were used. In keeping with the Delphi technique, the purpose of the round one questionnaire was to generate ideas and issues about clinical supervision in the healthcare setting. The purpose of the round two questionnaire was to firstly present the thematic analysis findings of round one and then ascertain if consensus of opinion could be reached for the themes and statements presented. ${ }^{36}$

\section{Participants}

In line with the Delphi process, purposive sampling was used to identify prospective participants to form the "expert participant" group. These were AHPs currently working in an acute tertiary hospital in Singapore who were actively engaged in supervision of a staff member (the supervisor) or receiving clinical supervision (the supervisee). A supervisee was defined as a newly qualified AHP who was required to participate in clinical supervision for at least a minimum of 1 year before gaining full registration. This aligned with the requirements for clinical supervision as outlined by the Allied Health Professionals Council of Singapore. ${ }^{10} \mathrm{~A}$ supervisor was defined as an AHP who with 3 years' experience in the Singapore setting. ${ }^{10}$ In this acute tertiary hospital setting in Singapore there was no prescribed role outlined for supervisors and the intensity of supervision was guided by the Allied Health Professionals Council of Singapore supervision requirements. ${ }^{10}$ Invitations to participate in the round one questionnaire were sent to the 408 AHP workforce in the Singapore hospital. These individuals represented allied health professions including, medical social work radiography, physiotherapy, occupational therapy and speech-language therapy (Table 1). Participants were excluded 
if they were not a supervisor or supervisee or were not AHPs. A total of $77(19 \%)$ participants (64 female and 13 male) completed the first round of the questionnaire. Mean age range was 20 to 30 years $(60 \%)$. The majority of participants were physiotherapists $(36 \%)$ (Table 1). The round two questionnaire was only sent to the participants who responded to the round one questionnaire. A total of 55 participants $(71 \%$ of the first round participants) completed the second round questionnaire.

Table 1. Participant Demographics

\begin{tabular}{lc}
\hline & $\mathbf{N}(\%)$ \\
\hline Gender & $64(83.1)$ \\
\hline Male & $13(16.8)$ \\
\hline Age Range & \\
\hline $20-30$ & $46(59.7)$ \\
\hline $30-40$ & $26(33.7)$ \\
\hline $40-50$ & $3(3.9)$ \\
\hline$>50$ & $2(2.6)$ \\
\hline Occupation & $4(5.1)$ \\
\hline Medical Social Worker (MSW) & $12(15.5)$ \\
\hline Occupational Therapist (OT) & $28(36.3)$ \\
\hline Physiotherapist (PT) & $14(18.1)$ \\
\hline Radiographer & $18(23.3)$ \\
\hline Speech Therapist (ST) & $1(1.3)$ \\
\hline Other & \\
\hline Years of experience in the acute hospital setting & $7(9.0)$ \\
\hline 0 to 1 & $13(16.8)$ \\
\hline 1 to 3 & $27(35.0)$ \\
\hline 3 to 5 & $20(25.9)$ \\
\hline 5 to 8 & $10(12.9)$ \\
\hline$>8$ &
\end{tabular}

\section{Instrument}

Round

One

The fit-for-purpose questionnaire used in round one was developed by the research team following a review of the literature on clinical supervision in healthcare settings. This review identified the following topics: (1) that people who engage in supervision have an understanding of what supervision is; (2) a shared understanding of their roles and responsibilities as both a supervisor and supervisee is important; (3) the topics that are typically brought to supervision by supervisees; (4) different supervision techniques that supervisors utilise; (6) the benefits and challenges of engaging in clinical supervision; and, (7) how clinical supervision is evaluated. ${ }^{2,3,5-8,13,16-19,21-26,28,29}$ As a result, open-ended questions were constructed with the purpose of capturing each topic area and examine AHP perspectives in the acute hospital setting in Singapore. Further open-ended questions were added to ensure participants could provide ideas for how to enhance clinical supervision in the workplace. The questionnaire was piloted with three AHP volunteers (a physiotherapist, occupational therapist and speech-language therapist) who were engaged in clinical supervision. The volunteers were asked to comment on various aspects of the functionality and content of the questionnaire. As a result of this feedback, minor wording changes were made to the questions.

The round one questionnaire consisted of two sections. The first section focused on demographic information such as age, occupation, gender and the number of years working in the organization. The second section of the questionnaire utilized thirteen open-ended questions designed to elicit responses based on ten topics related to current and future clinical supervision practice as identified from the review of the literature. The ten topics were: (1) defining clinical supervision; (2) roles and responsibilities of clinical supervision; (3) benefits of engaging in clinical supervision; (4) supervision techniques; (5) supervision topics; (6) outcome measures; (7) factors that impact the supervisory experience; (8 and 9) current and future challenges for engaging in clinical supervision; and, (10) ideas to enhance clinical supervision in their workplace. 


\section{Procedure - Round One}

Participants were invited to complete the online questionnaire via an email link from Qualtrics software. ${ }^{41}$ Reminder email messages were sent twice weekly for a period of two weeks to all eligible participants. The anonymity of all participants was preserved by generating a unique code, which was linked in a separate file with their email address, to ensure round two questionnaires were only sent to round one respondents.

\section{Instrument - Round Two}

The development of the round two questionnaire involved the thematic analysis of round one responses. ${ }^{42}$ In keeping with the thematic analysis methodology, this involved the research team members reading all participant responses, coding the responses and organising the responses into potential themes. The research team then met via Zoom and discussed the different themes that were extracted from the responses in order to reach agreement on the theme titles. ${ }^{43}$ The first researcher was responsible for developing statements under each theme, that were based on the responses with similar meaning. The full list of themes and statements was then further reviewed by the research team via Zoom and email. Where disagreement in interpretation occurred, the research team continued discussions until agreement was reached, and final amendments were made. Across the ten topics explored and responses gained, the research team extracted five overarching themes related to clinical supervision (Table 2).

Table 2. Five themes related to clinical supervision generated out of the round one questionnaire

1 Clinical tasks (CT): Responses relevant to clinical tasks such as bedside swallow assessments, mobility assessments, shower assessments, interviewing patients and communication with team members, clinical competency/meeting clinical standards and patient safety.

2 Professional development (PD): Responses related to professional development, learning, teaching and assessment techniques.

3 Emotions and support (ES): Responses related to stress, emotional support provided, lacking or suggested, role model, supervisory relationships and environment.

4 Time and human resources (TH): Responses relevant to time taken for supervision, juggling workload and supervision requirements, number of supervisors/staff.

5 Workplace administration (WA): Responses related to the requirements of the workplace such as time management, paperwork requirements of clinical supervision, organisation requirements and support.

The round two questionnaire was designed to support participants to provide their opinion of the relative value of the themes and statements generated from the round one questionnaire. To rate the value of each statement, a five-point Likert scale was used (1= strongly disagree, 2= disagree, 3= neutral, 4= agree, 5= strongly agree). ${ }^{44,45}$ Each statement included in the round two questionnaire is listed in the Appendix. The round two questionnaire was piloted with three AHP (physiotherapist, occupational therapist and speech therapist) who did not participate in the round one questionnaire. They were asked to pay particular attention to the vocabulary and sentence structure used to support appropriate readability for the English dialect spoken in Singapore and for non-native English-speaking participants. The feedback from pilot participants resulted in minor changes being made to several questions. For example, "When considering 'what does clinical supervision mean to you?', please indicate your level of agreement/disagreement with each statement" was changed to "Please indicate your level of agreement/disagreement to each statement: to me clinical supervision means"). The final questionnaire included sixty statements.

\section{Procedure Round Two}

An email containing information about the round two questionnaire and a clickable link to the questionnaire was sent to all participants who completed round one. Two reminder emails were sent to participants weekly over a two-week period (four in total).

\section{Data}

Analysis Round one questionnaire responses were subjected to thematic analysis. ${ }^{42}$ Demographic data was entered into an excel spreadsheet for descriptive analysis. Round two questionnaire results were reported as the means using the 5-point Likert scale. Likert scale responses of "agree" and "strongly agree" (4 and 5) were combined under the category of "agree" and coded as agreement for this study. "Neutral" (3), "disagree" (2) and "strongly disagree" (1) were combined under the category of "disagree." Categorising neutral under the category of "disagree" was a priori and is consistent with consensus definitions for other Delphi studies completed. ${ }^{21,46}$ Interquartile deviation (IQD) was calculated with values of $\leq 1.00$ regarded as an indicator of consensus. ${ }^{21}$ Percentage consensus was also calculated. Consensus agreement of participant responses for round two (i.e., respondent level of agreement with the statements) was set at $68 \% .45 \mathrm{An}$ item was regarded as reaching consensus if both percent agreement was 
$\geq 68 \%$ and IQD $\leq 1.00$. Finally, Cronbach's alpha was calculated to measure the level of consistency of opinion among the participants for each theme in round two of the questionnaire. A Cronbach's alpha value of 0.7 indicated fair consistency, 0.8 good level of consistency and 0.9 or greater was excellent consistency.

\section{RESULTS}

A total of 77 (19\%) participants (64 female and 13 male) completed round one of the questionnaire of the 408 AHP eligible to participate in the study (Table 1). A total of 55 participants (71\% of the first-round participants) completed the second round questionnaire. This represented an overall $13 \%$ response rate of AHPs working in the hospital.

The five themes that arose from round one questionnaire responses were: Clinical tasks (CT), Professional development (PD), Emotions and support (ES), Time and human resources (TH) and Workplace administration (WA) (Table 2).

The means and IQD for each statement and the percentage of participants who "agreed" or "strongly agreed" with the 60 statements included in the round two questionnaire are presented in the Appendix. Consensus was reached on 52 statements surrounding clinical supervision (Appendix). AHPs tended to agree most with statements linked with the themes of clinical tasks, professional development and workplace administration and as such demonstrated a common understanding of their current roles and responsibilities for clinical supervision for example filling knowledge gaps, growing the AHP profession, continued learning and reflective practice, mentoring support, clinical audits, a role model or "helpdesk". AHP agreed that challenges related to clinical supervision were protecting the time for clinical supervision and human resourcing for clinical supervision.

Within the 52 statements that reached consensus, seven statements about supervision were agreed to be not important (Appendix). These statements related to the themes of workplace administration (2 statements), emotions and support (1 statement) and professional development (4 statements). For example, clinical supervision did not need to provide the space for career advancement, or completion of administrative tasks, nor for engaging in professional development in order to provide clinical supervision.

Eight statements did not reach consensus with IQD values of more than 1 . These statements related to the themes of professional development ( 3 statements), time and human resources ( 2 statements) and no agreement for 1 statement each within the themes of clinical tasks, emotional support, and workplace administration. For example lack of agreement was related to suggested supervision challenges (impact of multiple supervisors, caseload, personality of supervisor, and lack of supervisors), ability to identify if a specific outcome measure was in use for supervision, quality supervision needing to include ongoing professional development requirements for senior staff, and improvements to the supervisory experience (the need for reducing paperwork surrounding clinical supervision and formal training for supervisors).

Cronbach's alpha for round two of the Delphi process ranged between 0.67 to 0.82 for the five themes (Table 3). The theme of professional development met the acceptable threshold of 0.8 or more indicating internal consistency in the responses to the statements within this theme. The themes of clinical tasks, workplace administration met the threshold of 0.7 indicating fair internal consistency. The themes of emotions and support and time and human resources were below 0.7 and indicate participants were not consistent in their responses and therefore close consideration should be given to the individual statements that met consensus rather than the broader themes.

Table 3. Cronbach's Alpha organised by theme

\begin{tabular}{lc}
\hline & Cronbach's Alpha \\
\hline Theme & \\
\hline Clinical tasks & 0.72 \\
\hline Emotions and support & 0.69 \\
\hline Professional development & 0.82 \\
\hline Time and human resources & 0.67 \\
\hline Workplace administration & 0.72 \\
\hline
\end{tabular}

(C) The Internet Journal of Allied Health Sciences and Practice, 2022 


\section{DISCUSSION}

This study utilized a modified Delphi approach to explore AHPs perspectives of clinical supervision in an acute care Singapore hospital. A total of five themes encompassing 52 statements were identified as important. Seven statements were not deemed important statements for understanding or engaging in clinical supervision. Several types of analyses (inter quartile, percent agreement score and Chronach's Alpha) were run in order to determine consensus and validity of the list of statements identified.

A number of interesting outcomes have emerged from this project. Firstly, the importance of clinical skills and discussions between the supervisor and supervisee to promote ongoing learning and development of reasoning skills were identified as consistent and core components of clinical supervision. These findings are consistent with recommendations for clinical supervision healthcare suggested in Proctor's model of Clinical Supervision, the CLEAR model, and the "Growth and Support" model.1,4-6 This suggests that the clinical supervision needs of AHP in the Singapore hospital setting are similar to the needs of other AHP working around the world. As such, hospitals in Singapore could consider incorporating existing supervisory models into a future supervision training program alongside culturally responsive supervisory practices that are unique to the Singapore context.

Time and human resourcing were identified as the challenges to enhancing current clinical supervision. These challenges are consistent with previous studies, as are the suggestions of protecting the time for supervision offered by the participants. ${ }^{16,24,47}$ In contrast with previous studies, clinical skills were not deemed to be a challenging aspect of clinical supervision. ${ }^{19,26}$ This may be due to the AHPs' regular use of their clinical skills within daily work requirements and as such participants did not fear being perceived as clinically incompetent.19,26 The finding could support clinical supervision moving beyond assessment of new graduates' clinical skills to focus on professional development and emotional support. ${ }^{27}$

Unexpectedly, the AHP participants demonstrated least agreement on or identified items that were not important items investigating their opinions of support from the organisation to engage in supervision, lack of supervisors, and supervisory style. These results differ from past studies which have suggested such factors are significant barriers to engaging in clinical supervision. ${ }^{3,16,24}$ As neither Singapore Health nor the focus organisation require a specific mode, model, or framework for supervision, it is suggested that participants in the current study did not have a formal model to reflect on. Instead, participants may have been reflecting more on the success or challenges of their individual experiences of supervision. This hypothesis could be further investigated via use of focus groups to better understand the reasons for lack of agreement and in turn support education on effective clinical supervision strategies.

In comparison, the need for a training package to support engaging in clinical supervision is supported in the literature for both AHP and Nursing. ${ }^{1,27,48-50}$ AHP participants in the Singapore hospital did not feel this needed to involve a formal qualification for supervisors. Instead, based on their consensus, we propose offering general ideas for areas of learning and development that capture both the body of research related to clinical supervision and AHP lived-experiences (e.g., study units on specific aspects of clinical supervision including giving feedback, models of supervision, building supervisory relationships, reflection on the experience of effective supervision, and roles and responsibilities in clinical supervision for supervisors and supervisees). These findings are consistent with previous research highlighting the positive relationship between supervisor training and feelings of confidence and competence in supervising. ${ }_{1,48,50}$ This is also in line with the literature reporting the value of dedicated supervisory units for nursing staff to enhance the quality of clinical supervision and promote learning. ${ }^{49}$ To ensure the training package is tailored to the Singapore hospital context and organisational culture, the themes and statements that reached consensus could serve as the foundation for defining the parameters of clinical supervision in the workplace. ${ }^{30-32}$

AHP participants also suggested that all staff engage in clinical supervision as a supervisee, regardless of length of time in the workforce. This finding is significant for health organisations in Singapore. Singapore Health requires only new graduate AHPs to participate in clinical supervision for their first year of employment. This contrasts with the requirement for all AHPs, regardless of experience, working in countries such as New Zealand and AHPs offering services under the National Disability Insurance Scheme (NDIS) in Australia.9-11 Finally, the consensus surrounding the importance of clinical supervision for engaging in professional development and clinical skill development suggests that despite the challenges of time, human resourcing, lack of training and differing teaching styles, clinical supervision is valued by AHP participants.

\section{Limitations and Future Directions}

The findings of the study must be considered alongside several limitations. First, a total of 77 round one participants represented approximately $19 \%$ of the total number of allied health staff in a single hospital in Singapore. This level of participation in a single hospital setting could indicate that the consensus statements do not reflect the views of all AHPs in the wider hospital or other hospitals in Singapore. Second, only 55 participants completed round two. The attrition rate of $26 \%$ may have led to self-selection 
bias. However, the retention rate between the two questionnaires does indicate interest in the project amongst participants, similar to other studies investigating aspects of clinical education. ${ }^{21}$ Participant attrition in Delphi-based studies is common as a result of "questionnaire fatigue". ${ }^{35}$ In addition, Further research is recommended to gain the views of other AHPs working in Singapore health settings and to identify any differences between professions. Given this finding, repeating the study in other hospitals may further enhance the understanding of the lived experience of clinical supervision in health settings in Singapore for AHPs.

Finally, there was a lack of internal consistency for the themes of time and human resources, emotions and support and statements defining clinical supervision and outcome measures for clinical supervision, despite the past research suggesting such themes be part of the clinical supervision process. 16,24,47 We propose this finding further highlights the need for an educational package to support both supervisor and supervisee understanding of scope of clinical supervision, the ways to evaluate clinical supervision and foster a supportive learning environment within the context and culture of the Singapore hospital setting.

\section{CONCLUSION}

This study has highlighted the importance that Singapore-based AHPs place on clinical supervision as part of clinical practice and professional development, knowledge of clinical supervision roles, responsibilities, teaching tools as well as highlighting current challenges and ideas for change. The findings are useful for managers of AHPs in Singapore and the wider hospital administrators. Given AHPs value clinical supervision, enhancing human resources, time, education and training could enhance understanding current practices and the roles and responsibilities when engaging in clinical supervision. In addition, the statements identified by the AHP participants are a useful starting point for creating a fit-for- purpose clinical supervision training package for hospital settings in Singapore.

\section{REFERENCES}

1. Lyth G. Clinical supervision: A concept analysis. Journal of Advanced Nursing. 2000;31(3):722-729.

2. Berggren I, da Silva AB, Severinsson E. Core ethical issues of clinical nursing supervision. Nursing \& Health Sciences. 2005;7(1):21-28.

3. Clouder L, Sellars J. Reflective practice and clinical supervision: An interprofessional perspective. Journal of Advanced Nursing. 2004;46(3):262-269.

4. Dawson M, Phillips B, Leggat SG. Effective clinical supervision for regional allied health professionals - the supervisee's perspective. Australian Health Review. 2012;36(1):92-97.

5. Winstanley J, White E. Clinical supervision: Models, measures and best practice. Nurse Researcher. 2003;10(4):7-38.

6. Hall T, Cox D. Clinical supervision: An appropriate term for physiotherapists? Learning in Health \& Social Care. 2009;8(4):282-291.

7. Titchen A, Binnie A. The art of clinical supervision. Journal of Clinical Nursing. 1995;4(5):327-334.

8. Gonge H, Buus N. Model for investigating the benefits of clinical supervision in psychiatric nursing: A survey study. International Journal of Mental Health Nursing. 2011;20(2):102-111.

9. Ministry of Health. Health Practitioners Competence Assurance Act 2003. https://www.health.govt.nz/ourwork/regulation-health-and-disability-system/health-practitioners-competence-assurance-act/about-health-practitionerscompetence-assurance-act. Published September 18, 2003. Accessed June 16, 2020.

10. Ministry of Health Allied Health Professions Council. Allied health Professions Council. https://www.healthprofessionals.gov.sg/docs/librariesprovider5/forms-and-downloads/080413_supervisionrequirements-_grace-period_ver1.pdf. Updated July 9, 2020. Accessed June 16, 2020.

11. Australian Government. National Disability Insurance Scheme (NDIS) Practice Standards and Quality Indicators. Version 3. https://www.ndiscommission.gov.au/sites/default/files/documents/2019-12/ndis-practice-standards-andquality-indicators.pdf. Published January, 2020. Accessed November 24, 2020.

12. Bruijn $M$, Busari J, Wolf $B$. Quality of clinical supervision as perceived by specialist registrars in a university and district teaching hospital. Medical Education. 2006;40(10):1002-1008.

13. Cross W, Moore A, Ockerby S. Clinical supervision of general nurses in a busy medical ward of a teaching hospital. Contemporary Nurse: A Journal for the Australian Nursing Profession. 2010;35(2):245-253.

14. Hall M, Poth C, Manns P, Beaupre L. To supervise or not to supervise a physical therapist student: A national survey of Canadian physical therapists. Journal of Physical Therapy Education. 2015;29(3):58-67.

15. Pront L, Gillham D, Schuwirth LW. Competencies to enable learning-focused clinical supervision: $A$ thematic analysis of the literature. Medical Education. 2016;50(4):485-495.

16. Cummins A. Clinical supervision: the way forward? A review of the literature. Nurse Education in Practice. 2009;9(3):215-220. 
17. Goorapah D. Clinical supervision. Journal of Clinical Nursing. 1997;6(3):173-178.

18. Hyrkäs K, Appelqvist-Schmidlechner K, Kivimäki K. First-line managers' views of the long-term effects of clinical supervision: How does clinical supervision support and develop leadership in health care? Journal of Nursing Management. 2005;13(3):209-220.

19. Sloan G. Good characteristics of a clinical supervisor: A community mental health nurse perspective. Journal of Advanced Nursing. 1999;30(3):713-722.

20. Sloan G. Clinical supervision: Beginning the supervisory relationship. British Journal of Nursing. 2005;14(17):918-923.

21. Chipchase L, Allen, S, Eley D, McAllister L, Strong J. Interprofessional supervision in an intercultural context: A qualitative study. Journal of Interprofessional Care. 2012;26(6):465-471.

22. Dawson M, Phillips B, Leggat S. Clinical supervision for allied health professionals: A systematic review. Journal of Allied Health. 2013;42(2):65-73.

23. Deery R. An action-research study exploring midwives' support needs and the effect of group clinical supervision. Midwifery. 2005;21(2):161-176.

24. Johns C. Clinical supervision as a model for clinical leadership. Journal of Nursing Management. 2003;11(1):25-34.

25. Rolfe G, Freshwater D, Jasper M. Critical Reflection for Nursing and the Helping Professions: A User's Guide. Basingstoke: Palgrave; 2001.

26. Touchie C, de Champlain A, Pugh D, Downing S, Bordage G. Supervising incoming first-year residents: Faculty expectations versus residents' experiences. Medical Educator. 2014;48(9):92-929.

27. Fitzpatrick S, Smith M, Wilding C. Clinical supervision in allied health in Australia: A model of allied health clinical supervision based on practitioner experience. The Internet Journal of Allied Health Sciences and Practice. 2015;13(4).

28. Koivu A, Hyrkäs K, Saarinen PI. Who attends clinical supervision? The uptake of clinical supervision by hospital nurses. Journal of Nursing Management. 2011;19(1):69-79.

29. Lynch L, Happell B. Implementing clinical supervision: Part 1: Laying the groundwork. International Journal of Mental Health Nursing. 2008;17(1):57-64.

30. Leggat SG, Phillips B, Pearce P, Dawson M, Schulz D, Smith J. Clinical supervision for allied health staff: Necessary but not sufficient. Australian Health Review. 2016;40(4):431-437.

31. McKenna B, Thom K, Howard F, Williams V; Te Pou o Te Whakaaro Nui, the National Centre of Mental Health Research, Information and Workforce Development. Professional Supervision for Mental Health and Addiction Nurses: A review of current approaches to professional supervision internationally and in the New Zealand mental health and addiction sector. Published January, 2008. Accessed November 16, 2020.

32. Te Pou, The National Centre of Mental Health Research, Information and Workforce Development. National Guidelines for the Professional Supervision of Mental Health and Addiction Nurses https://docplayer.net/10914916-Nationalguidelines-for-the-professional-supervision-of-mental-health-and-addiction-nurses.html. Published January, 2009. Accessed November 16, 2020.

33. Cheong K. Younger and more qualified allied health professionals join healthcare scene. https://www.straitstimes.com/singapore/health/younger-and-more-qualified-allied-healthcare-professionals-joinhealthcare-scene. Published February 17, 2015. Accessed January 10, 2017.

34. Bonner A, Stewart G. Development of competency based standards: An application of the Delphi research technique. Nurse Researcher. 2001;9(1):63-73.

35. Falzarano M, Zipp GP. Seeking consensus through the use of the Delphi technique in health sciences research. Journal of Allied Health. 2013;42(2):99-105.

36. Hasson F, Keeney S, McKenna H. Research guidelines for the Delphi survey technique. Journal of Advanced Nursing. 2000;32(4):1008-1015.

37. McKenna H. The Delphi technique: A worthwhile research approach for nursing? Journal of Advanced Nursing. 1994;19(6):1221-1225.

38. Powell C. The Delphi technique: Myths and realities. Journal of Advanced Nursing. 2003;41(4):376-382.

39. Tomasik T. Reliability and validity of the Delphi method in guideline development for family physicians. Quality in Primary Care. 2010;18(5):317-326.

40. Williams PL, Webb C. Clinical supervision skills: A delphi and critical incident technique study. Medical Teacher. 1994;16(2-3):139-157.

41. Qualtrics. Customer Survey Software. [software]. Available from: https://www.qualtrics.com/au/customerexperience/surveys/.

42. Braun V, Clarke V. Thematic analysis. The University of Auckland. https://www.psych.auckland.ac.nz/en/about/thematic-analysis.html. Published April, 2019. Accessed November 24, 2020. 
43. Zoom Video Communications, Inc. Zoom Client for Meetings. Version 5.5.0 [software]. Available from: https://zoom.us/download.

44. Vázquez-Ramos R, Leahy M, Hernández N. The Delphi method in rehabilitation counseling research. Rehabilitation Counseling Bulletin. 2007;50(2):111-124.

45. Vernon W. The Delphi technique: A review. International Journal of Therapy \& Rehabilitation. 2009;16(2):69-76.

46. Hui D, Bansal S, Strasser F, Morita T, Caraceni A, Davis M, et al. Indicators of integration of oncology and palliative care programs: An international consensus. Annals of Oncology. 2015;26(9):1953-1959.

47. Kumar S, Osborne K, Lehmann T. Clinical supervision of allied health professionals in country South Australia: A mixed methods pilot study. Australian Journal of Rural Health. 2015;23(5):265-271.

48. Geller E, Foley G. Broadening the 'ports of entry' for speech-language pathologists: A relational and reflective model for clinical supervision. American Journal of Speech-Language Pathology. 2009;18(1):22-41.

49. Nishioka VM, Coe MT, Hanita M, Moscato SR. Dedicated education unit: Nurse perspectives on their clinical teaching role. Nursing Education Perspectives. 2014;35(5):294-300.

50. Ross M. Implementing clinical supervision in mental health practice. Mental Health Practice. 2013;17(2):34-39. 


\section{APPENDIX: Percentage ratings, Means, and IQD for each statement ( ${ }^{*}$ statements considered not important, ** statements that did not reach consensus)}

\begin{tabular}{|c|c|c|c|}
\hline & $\begin{array}{l}\text { Percentage agreement } \\
(\%) \text { for scores } \geq 4\end{array}$ & MEAN & IQD \\
\hline \multicolumn{4}{|l|}{ Theme: Clinical tasks } \\
\hline Clinical knowledge / filling knowledge gaps & 100 & 4.76 & 0 \\
\hline Facilitates transition from academic studying to working and application of theoretical knowledge into clinical experience & 98 & 4.60 & 1 \\
\hline $\begin{array}{l}\text { Ensures the supervisee that should similar complex situations appear, supervisee will be able to know how to manage } \\
\text { and handle it independently and competently }\end{array}$ & 98 & 4.69 & 1 \\
\hline Work flow/ practical/clinical skills and techniques & 98 & 4.69 & 1 \\
\hline Guided teaching for clinical management and mentoring for more complex cases & 96 & 4.51 & 1 \\
\hline Ensures that the supervisee meets minimal clinical standards to ensure patient safety & 95 & 4.69 & 0 \\
\hline Ensures that treatment directions and plans are on the right track & 95 & 4.55 & 1 \\
\hline Improved competency and clinical skills perceived by supervisor and supervisee & 93 & 4.15 & 1 \\
\hline Clinical and documentation audits & 91 & 4.33 & 1 \\
\hline Bedside communication skills and aptitude & 87 & 4.25 & 1 \\
\hline Discharge planning & 84 & 4.44 & 1 \\
\hline An assessment of competency & 74 & 3.82 & 1 \\
\hline Lack of suitable caseloads** & 31 & 2.78 & 2 \\
\hline \multicolumn{4}{|l|}{ Theme: Emotions and support } \\
\hline More conducive and supportive environment for learning & 96 & 4.55 & 1 \\
\hline A role model of ethics and values of practice & 95 & 4.60 & 1 \\
\hline Prevents clinical stagnation, burnout, helplessness or isolation & 93 & 4.44 & 1 \\
\hline Contributes to the development of a good working culture & 86 & 4.24 & 1 \\
\hline Emotional and verbal encouragement and support from supervisors & 82 & 4.13 & 1 \\
\hline Developing rapport and teamwork within the organization and department & 79 & 4.02 & 1 \\
\hline A supervisor being readily available (or being a "helpdesk") & 79 & 4.07 & 1 \\
\hline Personality differences and learning or teaching styles of supervisee or supervisor & 75 & 3.85 & 0.5 \\
\hline A period of stress* & 65 & 3.65 & 1 \\
\hline $\begin{array}{l}\text { Support as a friend for clinical and non-clinical work with open and non-judgmental discussions for clinical and non-clinical } \\
\text { work** }^{* *}\end{array}$ & 71 & 3.89 & 2 \\
\hline \multicolumn{4}{|l|}{ Theme: Professional development } \\
\hline Providing guidance, knowledge and support for the younger generation of AHPs & 100 & 4.82 & 0 \\
\hline Facilitates continued clinical learning and development & 100 & 4.78 & 0 \\
\hline Allows the profession to grow as a whole and improve the profession & 100 & 4.69 & 1 \\
\hline Difficulties faced in the session and areas for improvement & 100 & 4.71 & 1 \\
\hline Supports and allows the supervisee to reflect on his/her own clinical skills & 98 & 4.53 & 1 \\
\hline Facilitates learning via case discussions & 98 & 4.69 & 1 \\
\hline
\end{tabular}

(c) The Internet Journal of Allied Health Sciences and Practice, 2022 
A means of clinical and professional development for myself

\begin{tabular}{|c|c|c|}
\hline 97 & 4.40 & 1 \\
\hline 93 & 4.53 & 1 \\
\hline 93 & 4.51 & 1 \\
\hline 93 & 4.25 & 1 \\
\hline 93 & 4.36 & 1 \\
\hline 87 & 4.24 & 1 \\
\hline 86 & 4.22 & 1 \\
\hline 84 & 4.40 & 1 \\
\hline 82 & 4.22 & 1 \\
\hline 76 & 4.00 & 1 \\
\hline 74 & 3.87 & 0.5 \\
\hline 64 & 3.60 & 1 \\
\hline 62 & 3.60 & 1 \\
\hline 56 & 3.60 & 1 \\
\hline 56 & 3.53 & 1 \\
\hline 75 & 4.09 & 1.5 \\
\hline 73 & 3.96 & 2 \\
\hline 13 & 2.36 & 2 \\
\hline 96 & 4.65 & 1 \\
\hline 84 & 4.18 & 1 \\
\hline 82 & 4.29 & 1 \\
\hline 80 & 3.98 & 1 \\
\hline 76 & 3.96 & 1 \\
\hline 73 & 4.07 & 2 \\
\hline 64 & 3.60 & 2 \\
\hline 93 & 4.33 & 1 \\
\hline 86 & 4.11 & 1 \\
\hline 68 & 3.76 & 1 \\
\hline 58 & 3.64 & 1 \\
\hline 53 & 3.44 & 1 \\
\hline 66 & 3.95 & 2 \\
\hline
\end{tabular}

Promotes self-reflection on clinical skills

Feedback from both supervisor and supervisee

Development of a clinical supervisory unit or framework for learning

Personality, level of dedication towards learning and teaching and learning style of supervisee / supervisor

Greater variety of clinical supervisory courses available

All staff (including supervisors/seniors) to obtain clinical supervision and learning

Ensures that clinical development and career growth is on the right track

Availability of a structured learning programme for the developing of clinical skills

Supports and assists in setting up the supervisee's personal development and career plan

Supervisors have stopped receiving professional development themselves*

Lack of knowledge about potential career paths and development opportunities established by the management*

Having a distinct and well-considered career advancement plan that is agreed upon by supervisor and supervisee *

Lack of clear structure, framework and culture for supervision in the organisation and department*

Certified qualifications of clinical supervisory courses**

Opportunities for senior staff to also receive supervision and clinical learning**

No specific outcome measure for clinical supervision ${ }^{\star *}$

Theme: Time and human resources

Dedicated and protected time allocated to clinical supervision

Manpower shortage of supervisors due to poor retention rate

Increase in number of supervisors

Amount of experience that the supervisor has at supporting supervisees

Lack of training for new supervisors

Lack of supervisors**

Having multiple supervisors who have different clinical management styles ${ }^{* *}$

Theme: Workplace administration

Information / ad-hoc consultation regarding administrative and clinical questions

Discussion regarding administrative duties (e.g. workflow) and administrative protocols to ensure everyday ongoing administrative duties are covered

More administrative work responsibilities including paperwork

Lack of support and direction from the government about clinical supervision for professionals*

Coaches the supervisee on how to perform administrative duties*

Less paperwork/administration involved in clinical supervision ${ }^{\star *}$

(c) The Internet Journal of Allied Health Sciences and Practice, 2022 